attack of indigestion set in. Next day he had much pain and tenderness in the gastro-hepatic region, accompanled by slight jaundice and retching. Collapse set in, and he died on July 20 th. There was evidently chronic disease of the liver, possibly malignant.

\section{CASE CXXviII}

Hospital patient, sent by Dr. Lloyd Williams, Stone, Staffordshire. Vesical calculus removed by litholapaxy two years previously Catheter employed for three years. Residual urine $2 \mathrm{sz}$., foul, alkaline, containing much pus ; specife gravity rox 2. On September 28th, I904, I removed the prostate, which weighed $3 \frac{1}{4} \mathrm{oz}$. The operation was easily accomplished and well borne, but the patient died uraemic on October sth. The kidneys were found extensively diseased.

CaSE CXXXVIII.

Gentleman, aged 72, brought by Dr. F. W. Wright, South Godstone. Was in great distress from over-distended bladder, with extreme frequency of micturition. Would not employ a catheter. Suffering from an enormous naso-pharyngeal growth, blocking both nostrils, which had recurred after repeated removal and general catarrh of the air passages. On October 3 rst, r904, I removed the prostate, weighing $3 \frac{1}{2}$ oz., easily and rapidly. There was scarcely any bleeding or shock, and in the evening his condition was quite satisfactory. Early next morning, however, the breathing became rapid and laboured, and there was inability to cough up the accumulation of mucus in the bronchi. The bronchial symptoms increasing rapidly, the patient died that evening of heart fallure. Though chloroform was employed, the bronchitis would seem to have been induced by the anaesthetic facllitating the accumulation of mucus in the bronchi in a patient the subject of chronic catarrh with naso-pharyngeal growth.

\section{CASE Cli.}

Gentleman, aged 70, seen with Dr. W. Y. Orr, of Patney. Prostatio symptoms had existed for six years, culmipating in retention of urine November 28 th, r904; catheter passed with difficulty, and about a quart of urine with blood drawn off. On December 5th, Mr. Watson Cheyne being present, I removed the prostate, which weighed $4 \frac{1}{\frac{1}{3}} \mathrm{oz}$., with great ease in five minutes, with scarcely any bleeding. The patient was extremely restless and excited the whole day after the operation. Urine very freely secreted for two days, but was of pale colour and devoid of the usual odour. Then it became scanty, and the patient died uraemic on December 8th. There was no autopsy, but doubtless the kidneys were diseased from the backward pressure of the urine for years.

\section{Case clxx.}

Hospital patient, aged 69, sent by Dr. J. G. Blackman, Portsmouth. Cathether employed for fifteen years; entirely dependent thereon for two years. Frequent attacks of cystitis and bleeding. Urine contained much pus, but patient seemed in very fair health and a.favourable subject for operation. On March 8th I enuoleated the prostate easily and rapidly-in five minutes; there was practically no bleeding or shock. Beyond some retching after operation progress was satisfactory for forty-eight hour's, but on the evening of March roth severe vomiting set in, followed by collarse, and the patient died early next morning. No autopsy was allowed.

REFERENCES

1 July 2oth, rgor ; February r8t, July $26 \mathrm{th}$, November 8 th, rgo2 ; July 4 th, October 17th, x903; May 21st, October 29th, 1904.

\section{TREATMENT OF TUBERCULOSIS AND TUBER- CULIN INOCULATION.}

BY T. WARREN BROWN, M.R.C.S.ENG., L.R.C.P.LOND. Wallington.

THE treatment of tuberculosia by tuberculin being somewhat new, and comparatively few cases having been reported, a description of a case which has been under my care for a year may not be without interest.

The patient is a young lady aged 16, who when first seen by me in February, 1904, was suffering from subacute cystitis. Previously she had passed a few drops of blood at the end of micturition with some pain, but little attention was paid to this fact until I saw her and learned from her mother that her urine was thick and there was pain alter passing it, and sometimes blood, and that she was disturbed several times during the night owing to the frequent desire to micturate. On examination I found the urine contained pus and a trace of blood with some calcium oxalate crystals, and treated the case as one of ordinary cystitis ; when, however, no sign of improvement occurred I sent a specimen of the urine for examination for tubercle bacilli and received the following report:

Specific gravity ror6, faintly acid, albumen small amount, blood a trace, sugar absent. The deposit is excessive owing to a moderato amount of pus: With this is a very little blood and an excess of vesical epithelium ; some of the cells appear to come from the deeper layers of the vesical mucosa. No casts or renal cells. Some minute crystals of calcic oxalate. Tuberele bacilli are present in small numbers.

This satisfied me that the case was one of tuberculous ulceration of the bladder, and desiring to ascertain ity + xtent I, in consultation with Mr. Pardoe of St. Peter's Hospital, obtained a complete cystoscopic examination of the interio of the bladder. On the right side of the neck was a smaIl ulcer, and around the orifice of the right ureter another pati $h$. On pressing the right kidney turbid fluid passed ont of the orifice of the right ureter; there were also several nodules scattered over the mucous membrane of the bladder, but clear urine was pressed out of the left ureter. This examination clearly showed right ascending tuberculous cystitis. The patient was put on general treatment with plenty of fats and urinary antiseptics, urotropine and salol āà gr. $v$, tr. bellad. $m \times$ t.d.s., also ol. santal flav. $m x$ in capsules t.d.s. She remained on this treatment until June 14th, 1904, when she was getting worse, the pain requiring morphine suppositorit s every night. I again consulted Mr. Pardoe, and we agreed to start the tuberculin treatment, to which her parents readily consented. I. started with Koch's T $R$, which I obtained in measured doses from Messrs. Allen and Hanburys, beginning with the minute dose of zं $\mathrm{mg}$., gradually increasing it every two days. At first no great reaction occurred beyond a slight temperature of $100^{\circ}$; when 1 mg. was reached the temperat ure went up to $102.2^{\circ}$, and pain became very severe; with ${ }^{1}$ mg. the temperature was 105. $4^{\circ}$ with rigors and malaise, but strange to say the pain became better. Owing to this strong reaction I returned to $\frac{1}{4} \mathrm{mg}$. which canged fair reaction and temp+rature $105^{\circ}$. I kept at this strength every other day for a week, the temperature returning to normal. I then again started on $\frac{1}{2} \mathrm{mg}$., which gave a reaction with temperature $103.8^{\circ} \mathrm{F}$. After this I injected $\frac{1}{2} \mathrm{mg}$. every four days for about one month, and, as the patient responded in no way to this strength, the temperature keeping normal, I increased the dose to $\frac{3}{4} \mathrm{mg}$, this only giving a temperature of $100^{\circ} \mathrm{F}$. The $\frac{9}{4} \mathrm{mg}$. was kept up for about one month, then $1 \mathrm{mg}$. was reached, which caused only slight reaction. The patient is still receiving injertions of this strength once a week, and is very much better in all respects-pain very slight, micturition less frequent, and the urine almost clear, with no tubercle bacilli. The weight of the patient. was increased about $2 \mathrm{lb}$. a month during the treatment. After three months of tuberculin treatment the bladder was again cystoscoped by Mr. Pardoe, who found the ulcers healed and in their place puckered scars, but there were still present the scattered nodules. It is to be hoped that these are undergoing retrograde changes, and that the disease has been cured. The patient is now living at Westcliffe-onSea, where she is under the care of Dr. Day, who still continues the inoculations from an immunizing as well as curative point of view. This patient's disease is localized to the bladder, and all the other organs of the body are normal I therefore consider it was a most suitable case for the tuberculin treatment, and I do not hesitate to say that the latter has been the means of curing a disease which has always been looked upon as of progressively downward character.

\section{TREATMENT OF SEA-SICKNESS}

\section{By J. METCALFE SHARPE,} Surgeon, R.M.S. Ultonia.

As the treatment of this troublesome malady is, up to the present, somewhat indefinite, I desire to advance a theory which I hold is not altogether impracticable, and which, as ship surgeon in both the Cunard Steamship Company and P. and O. S. N. Company, I have found helpinl to more than one sufferer.

Assuming that sea-sickness is a reflex action of the stomach to a central stimulus, it occurred to me that the stimulus must enter the brain by one or more of the special sense tracts. I found that the vomited material in five cases of uncomplicated sea.sickness compared in reaction with the vomit in certain organic diseases of the nervous system, namely, locomotor ataxy, etc., being very acid, the acidity being due to lactic acid, and, to a lesser degree, free hydrochloric acid. The examination was conducted in each case fifteen minutes alter the administration of food. The test used was the following :

Add to a 5 per cent. solution of carbolic acid two or three drops of a solution of perchloride of iron, until fluid is a pale amethyst blue. To this add a few drops of contents of stomach, when, if lactic acid is present, the colour will change to a canary yellow.

Again, the vomiting of sea-sickness is "persistent," and occurs after everpthing taken into the stomach; that is to say, the simplest and least irritating articles of food are as 
liable to bo rejected as those which might be supposed to cause some embarrassment to the stomach.

Granted, then, that sea-sickness is a nervous vomiting, and that the reflex action is transmitted by the vagi to the solar plexus, the question arises, What is the origin of the stimulus?

By paralysing the accommodation of one eye, that is to say, converting one pye into an "ametropic" and allowing the other to remain "emmetropic," it was found that the intensity of the symptoms was greatly ameliorated. During the last twelve months at sea I have collected reports on 50 cases so trested; 65 per cent. were relieved in from six to twentyfour hours; the method of treatment being: Two or three drops of a solution of atropine ( $4 \mathrm{gr}$. to the ounce) or other mydriatic were dropped into one eye daily, after a satisf actory examination with the ophthalmoscope, etc., or where the patient objected one eye was merely bandaged; thus, by altering the principal focus, the motion of objects on board a ship (which no doubt forms the impulse) is not so uniformly transmitted to the brain. Nine of the above cases are more or less blind in one ese. and have not experienced sea-sickness since blindness. One recent case I will cite, as being a striking example of the effects of unilateral blindness on sea-sickness :

D. M , aged 50 years. First-class passenger, R.M.S. Etruria, has crossed western ocean two or three times a year in "Cunard liners" since 1887 . Suffered severely from sea-sickness every trip until 1896. In 1894 consulted an oculist, when both eyes were certifled to bo "emmetropic." In January, 1896 , vision in left eye was found to be $\frac{1}{4}$ (afterwards becoming entirejy lost). Cause not known. In February, 1896, he again crossed, and has since continued to do so as regularly as before, but has not since experienced any feeling of sea-sickness.

In conclusion, should like to add a few remarks re the administration of chloral hydrate in this malady. As a hypnotic and depressant of the vagi centres large doses are required; but; unfortunately, large doses act as a gastric irritant, and thus the tendency to vomit is increased; consequently only a small dose of the drug is retained and absorbed, which acts as a stimulant to the vagi centres. The only satisfactory way to administer chloral hydrate in obstinate cases of sea-sickness is by the rectum in doses of from 20 to $30 \mathrm{gr}$.

The important question of the treatment of sea-sickness, which strikes fear into the hearts of thousands of people who are compelled by basiness or otherwise to cross the ocean, demands special attention. As the present system of treatment by soporifics and general depressants is, at the most, symptomatic, and dangers may arise from not knowing the idiosyncrasies of your patients (which obviously ship surgeons cannot), I felt compelled to abandon it.

I am indebted to Dr. Johnson, Cunard liner R M.S. Etruria, for reports on some of the cases.$$
\text { MEMORANDA: }
$$$$
\text { MEDICAL, SURGICAL, OBSTETRICAL, THERA- }
$$$$
\text { PeUtical, Pathological, Etc. }
$$

THE IDENTIFICATION OF MOSQUITOS.

I wound like to take this opportunity of drawing the attention of those who are interested in the subject to an error which I noticed in a note on Anopheles (cellia) pharoensis in the first report of the Wellcome Research Laboratories at the Gordon Memorial College, Khartoum. Mr. Theobald says : "It also extends into Arabia, having recently been sent to me from the Aden Hinterland." In May, 1904, when in medical charge of the lines of communication at Nobat Dukaim, I sent a fow specimens of an Anopheles which I was then studying to $\mathrm{Mr}$. Theobald, with a note to say I thought it was a new species but was related to $A$. rossii and A. ludlowii. . Mr. Theobald wrote back, and said my Anopheles was Anopheles wellcomei. I was unable to compare this mosquito with Anopheles wellcomei. so I awaited the publication of the above report. I had, in the meantime, sent some specimens to Liverpool as Anopheles wellcomei. The report appeared in September, 1904, and later I heard from Liverpool that my specimens were not Anopheles wellcomei. Since then I have read the description of Anopheles vellcomei, and have compared it with my specimens, and find it is most certainly not the same mosquito. I therefore wish to state that mine is a new species, and has been named Anopheles arabiensis. I need hardly say that the note on Anopheles pharoensis is meant for Anopheles wellcomei. I have studied all the Cnlicidae in the Aden Hinterland as far as I was able, and never once came across any Anopheline that could be placed in the genus cellia.

It will be easily understood that it is an exceedingly difficult matter identify ing a mosquito from a dried adult female, so much depends on the scale ornamentation; but to one who is on the spot and has the opportunity of examining countless numbers of fresh specimens and of studying the eggs and larvae, and comparing these with the accurate descriptions of the known mosquitos, it is far simpler.

Anopheles arabiensis is the most important malaria carrier in the Hinterland. Malaria is the prevailing disease, and is mostly malignant tertian. I hope shortly to publish my descriptions of five new Anopheles, giving full details of eggs and larvae.

subbulpore.

W. Scotr Patton, M.B., Lieut. I.M.S.

EXERCISE AND OPEN-AIR TREATMENT OF PHTHISIS. Now, when we hear so much about the open-air treatment of consumption, I cannot help writing a few lines strongly to endorse the statement made by Dr. Hughes of the Westmorland Sanatorium regarding exercises (BRITISH MEDICAL JournaL, April 22nd, page 883). I can recall cases, happily not very numerous, when I have seen tuberculous mischief in the lung in young men powerfully helped on its course by a trip to switzerland. The patient goes with friends, and is encouraged by them to exert himself in long walks from which he returns fevtred and exhausted.

Too much stress is now laid on exercise. One may see a consumptive invalid walking daily in all weathers; he tells you he is "doing the open air cure." The truth being that he is dangerously overdoing what he calls the air cure. Put such a one on the plan of rest, good food, and pure air, and an improvement is pretty certain to follow. When a tuberculous patient begins to show signs of gout in his system then the case becomes very hopeful.

With regard to air treatment, I should like to say that there seems to me to be a tendencs to a non-tuberculous form of disease in the left lung apex as a result of breathing close air. In a book I wrote on the climatic treatment of consumption many vears ago, I referred to the cases of seamen who were invalided from an old man of war with what the surgeon called "pulmonary cachexia." The disease was evident at the left lung apex, and was attributed to the very close atmosphere in which the men slept. Most of these cases recovered completely. I have myself observed cases in which a crepitant râle at the left apex has made one fear the advent of tuberculosis, but many of them have recovered perfectly under treatment. One such I had under observation last year. The youth was a hard-working dental student, and my diagnosis was confirmed by an able second opinion. Treatment with sodium hypophosphite, pure air and rest seems perfectly to have restored this man, for now no morbid sounds can be heard in the lungs. There were no bacilli in the sputum.

Cases of this class in young overworked men and women ought certainly to benefit greatly in a well-managed sanatorium.

Bognor.

John C. Thorowgood, M.D., F.R.C.P.

\section{CAMPHOR POISONING : A NOTE.}

IN discussing camphor poisoning the authorities give descriptions which are more varied than convincing, and treat the fact that convulsions occur with an almost contemptuous brevity.

I have been called to two cases, and in each I was warned that " the patient was dead." My father, Dr. Leonard Grant, has also seen one case, and the message sent was to the effect - "Sister has died in a fit." Althougb, however, neither of us has seen any of these attacks, the history of one of my cases is so striking that I submit it.

A police-constable was called to see a man who had taken poison, and found him apparently dying. While the officer was preparing an emetic the patient vomited and seemed to get immediately well, but the officer decided to take him to the hospital, whither he walked with ease. The housephysician on duty was unable to find anything to support the history, so the man was taken to the police station.

While the constable was explaining the matter to the inspector the prisoner was seized with a convulsion, which rapidly passed into collapse and of such a character that even an officer of this experience added to his request that I should come, "I think the man is dead."

I was at the station in less than ten minutes, and found the patient standing. He smelt strongly of camphor, as did also 